\title{
nature
}

The opinion that this journal should not have published a famous article on solute-free solutions overlooks the multivalent function of a general journal of science.

Naturally, but mistakenly, a handful of readers (and some others) are perplexed that Nature should have published the article by Dr Jacques Benveniste and his associates (333, 816; 1988) reporting the unbelievable circumstance that solutions of a biological reagent retain their activity even when diluted beyond the point at which molecules of the active ingredient can persist. One view, ably put by Dr Henry Metzger on page 375 , is that the publication of irreproducible data, as distinct from speculative opinion, requires that more exacting editorial standards should apply. Otherwise, he says, the process of science is confused, even lent a "circus atmosphere".

Metzger goes on to echo a not disinterested toffee-nosed opinion recruited last week by the New York Times that journals such as this should not lend their reputation to spurious science by publishing it; Metzger uses the word imprimatur.

Sadly, real science is less perfect and the truth is more complicated. General journals such as this are afflicted by a torrent of heterodox would-be literature offered for publication. Proofs of the error of special relativity are the stock of this trade, but novel theories of mind are catching up. Deciding what to do is usually simple, which is not to imply that dealing with these unpublished manuscripts is straightforward; the authors are usually zealous correspondents - which, given the enormity of their claims, is natural enough. But it is rare that some such claim should come from a government-supported laboratory, that its principal author should urge publication in the face of common sense and should complain that failure to publish will be tantamount to the suppression of the truth. The antecedents of the Benveniste publication are as exceptional as its sequel.

Moreover, there is no absolute rule that journals such as this, which are proud to publish a great deal of original science, should not on occasion give an airing to material that is different in kind. Indeed, there are occasions when publication of spurious science may be a public service. Some readers may recall the case of scotophobin, a protein supposed to reside in the brains of trained rats which, when injected into the brains of naive rats, would transfer the first rat's learned capacity to run a maze, for example. Nature published a version of such a manuscript after several preliminary accounts had appeared elsewhere, but accompanied it with a devastating critique from $\mathrm{Mr}$ Walter W. Stewart (see Nature 238, 198-210 1972). Nothing much has been heard of scotophobin since. Is not a little of the "circus atmosphere" inescapable on these occasions?

Not that belief in the magical properties of attenuated solutions will be as quickly exorcised. Since the emergence of homoeopathic medicine in the early nineteenth century, before the atomic theory had been properly established, the theory of biological activity at extreme dilution has been a theory in search of verification. It would be naive to expect that the hunt for verification will now be abandoned simply because Nature's opinion of Benveniste's experiments is unsatisfactory. When a quarter of French physicians prescribe homoeopathic medicines, there is plainly too much at stake for the issue to be dropped. This journal will keep an eye on this interesting field, with its implications that the law of mass action must be repealed. That is consonant with the function of a general journal of science.
Strictly academic journals have simple rules to follow when deciding what to publish. General journals such as this, whose function is not only to publish excellent original science but to keep a general readership well-informed, necessarily have other fish to fry as well. Merely reporting events will not always suffice. But the two functions are complementary, for who can pretend, alas, that excellent science is the whole of science?

\section{When less means less}

\section{Britain plans to spend less and less on research,} but has not explained why.

UNDERSTANDING British policy on research has become a task comparable with that of guessing what may lie behind the latest moves by one's opponent in a game of chess. The game the British government is playing on the financing of research may have the admirable quality of consistency, but its objectives are entirely obscure. For chess-players, that is a splendid posture; the interesting question is whether it can be appropriate in the conduct of public policy. Two documents appearing last week illustrate why it is not.

First, there is the now-annual review of the Advisory Board for the Research Councils (ABRC), this year as always a repetition of Oliver Twist's familiar theme of "More, please!" (see Nature 334, 279; 1988). As the years go by, the tone of this demeaning request is increasingly despondent.

Again, much of the board's need of extra cash stems from its wish, consistent with government ambitions, to assist with the "restructuring of the science base", which is another name for the further amalgamation of institutes and laboratories. The request is repeated partly because last year's extra cash was swallowed up by nationally negotiated increases of university pay. Yet $A B R C$ also notes the continuing decline of British contributions to the international literature of science, again zealously recorded by John Irvine and Ben Martin from the University of Sussex. Actual spending through the research council system, $£ 699$ million this year, is planned to increase by 0.4 per cent between now and next year (when inflation is likely to exceed 5 per cent a year) and, thereafter, to fall in cash terms.

Why should Britain be cutting back on research when governments elsewhere are doing the opposite? Sadly, there seems to be no answer. But the annual review by the Cabinet Office of public support for research and development (see page 374) faithfully catalogues the downward trend - a decrease of 3 per cent between 1985 and 1986 will be followed by a further decrease of 7 per cent by the end of the decade. The only good thing to be said for this pattern is that defence research will bear the brunt of the decline.

Oddly, no explanation is given. The most plausible theory is that the British government has decided that its own economies on research will force industry to spend instead. In the past year, there has indeed been an increase of the total volume of research spending of $£ 250$ million, but more than 70 per cent of the extra was spent by the British subsidiaries of overseas corporations. That seems to be a high-risk strategy. 